\title{
SMART NURSE CALL BERBASIS MIKROKONTROLER ARDUINO UNTUK KOMUNIKASI ANTARA KAMAR PASIEN DENGAN PERAWAT MENGGUNAKAN ANDROID
}

\author{
M. Fahmi Erfan ${ }^{1}$, Anang Widiantoro ${ }^{2}$ \\ ${ }^{1,2}$ Teknik Elektro, Universitas Muhammadiyah Surabaya, \\ Jl.Sutorejo No.59 Surabaya, Jawa Timur, Indonesia
}

E-mail: fahmierfan99@gmail.com, anang_widiantoro@yahoo.com

\begin{abstract}
Abstrak - Rumah sakit adalah gedung tempat menyediakan dan memberikan pelayanan kesehatan yang meliputi berbagai masalah kesehatan. Rumah sakit juga memberikan fasilitas berupa kamar untuk menginap bagi pasien yang memerlukan perawatan lebih lanjut. Setiap kamar dari rumah sakit dilengkapi dengan fasilitas-fasilitas yang baik untuk memantau perkembangan kesehatan pasien. Dalam suatu rumah sakit, pasien yang menginap memerlukan bantuan dari para tenaga kesehatan baik perawat maupun dokter ahli. Pada saat pasien membutuhkan bantuan, seringkali orang yang sedang menjaga pasien tersebut meminta bantuan perawat secara manual dengan memanggil perawat yang sedang berada di ruang jaga perawat atau melalui telepon yang disediakan pada tiap-tiap kamar.

System smart nurse call berbasis mikrokontroler arduino sebagai perantara komunikasi wireless antara kamar pasien dengan android di ruang jaga perawat adalah sebuah alat komunikasi antara ruang kamar pasien dengan ruang perawat memanfaatkan sistem wireless yang terhubung dengan mikrokontroler sebagai otak dari alat kerja tersebut. Perancangan prototype system smart nurse call menggunakan beberapa komponen utama push button, mikrokontroler arduino uno dan ethernet shield 911105A,TPLINK,Hp android, modul df player, speaker, LED. Push button sebagai inputan arduino uno dan ethernet shield kemudian diproses, TP-LINK adalah sebagai penghubung wireless dengan mikrokontroler arduino uno dan ethrtnet shield, kemudian hp android sebagai alat untuk monitoring bead head kamar pasien, Modul df player adalah modul MP3 dengan output yang telah disederhanakan langsung ke pengeras suara. Speaker sebagai output dari df player yang mengeluarkan suara panggilan kepda perawat, LED sebagai indikator pada kamar pasien bahwa pasien sedang membutuhkan bantuan.

Dengan adanya prototyp smart nurse call kita dapat memonitoring pasien dengan menggunakan $\mathrm{hp}$ android dan suara panggilan melalui panggilan speaker dan terdapat indikator lampu LED pada kamar pasien.
\end{abstract}

Kata Kunci : Arduino uno, Ethernet shield, TP-LINK, Android, Df player

Abstract-A hospital is a building that provides health services to cover a variety of health problems. It also provides facilities in the form of rooms to stay for patients who need further treatment. Each room of the hospital is equipped with good facilities to monitor the progress of the patient's health. In a hospital, patients who stay overnight need help from health workers both nurses and expert doctors. When a patient needs help, often the person who is looking after the patient asks the nurse for help manually by calling the nurse in the nurse's guard room or by telephone provided in each room.

Smart nurse call system based on arduino microcontroller as an intermediary for wireless communication between the patient's room and android in the nurse's nurse room is a communication device between the patient's room and the nurse's room utilizing a wireless system connected to the microcontroller as the brain of the work tool. The prototype design of the smart nurse call system uses several key components, push button, arduino uno microcontroller and $911105 A$ ethernet shield, TP-LINK, Android phone, df player module, speaker, LED. Push button as an arduino uno and ethernet shield input then processed, TP-LINK is a wireless link with the arduino uno microcontroller and the ethrtnet shield, then the android phone as a tool for monitoring bead head patient rooms, df player module is an MP3 module with a simplified output module directly to the speaker. Speaker as the output of the df player that makes a call to the nurse, the LED as an indicator in the patient's room that the patient is in need of help.

With the prototype smart nurse call, we can monitor patients using an android phone and voice calls through speaker calls and there are LED light indicators in the patient's room.

Keywords : Arduino uno, Ethernet shield, TP-LINK, Android, Df player

\section{Pendahuluan}

Rumah sakit adalah gedung tempat menyediakan dan memberikan pelayanan kesehatan yang meliputi berbagai masalah kesehatan. Rumah sakit juga memberikan fasilitas berupa kamar untuk menginap bagi pasien yang memerlukan perawatan lebih lanjut. Setiap kamar dari rumah sakit dilengkapi dengan fasilitas-fasilitas yang baik untuk memantau perkembangan kesehatan pasien. Dalam suatu rumah sakit, pasien yang menginap memerlukan bantuan dari para tenaga kesehatan baik perawat maupun dokter ahli. Pada saat pasien membutuhkan bantuan, seringkali orang yang sedang menjaga pasien tersebut meminta bantuan perawat secara manual dengan memanggil perawat yang sedang berada di ruang jaga perawat atau melalui telepon yang disediakan pada tiap-tiap kamar.

\section{TINJAUAN PUSTAKA}

Smart Nurse Call adalah alat untuk pemanggil perawat menggunakan system wireless dengan input dari push botton dan output menggunan Android.

\section{A. Arduino}

Arduino UNO R3 adalah sebuah board mikrokontroler yang didasarkan pada ATmega328 (datasheet). Arduino UNO mempunyai 14 pin digital input/output (6 di antaranya dapat 
digunakan sebagai output PWM), 6 input analog, sebuah osilator Kristal $16 \mathrm{MHz}$, sebuah koneksi USB, sebuah power jack, sebuah ICSP header, dan sebuat tombol reset. Arduino UNO memuat semua yang dibutuhkan untuk menunjang mikrokontroler, mudah menghubungkannya ke sebuah computer dengan sebuah kabel USB atau mensuplainya dengan sebuah adaptor AC ke DC atau menggunakan baterai untuk memulainya dimasukkan pada pin header Gnd dan Vin dari konektor daya.

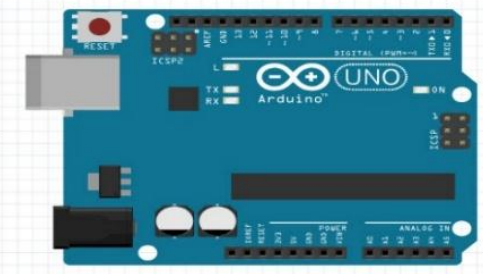

Gambar 1. Arduino UNO R3

\section{B. Arduino Ethernet Shield}

Ethernet Shield menambah kemampuan arduino board agar terhubung ke jaringan komputer. Ethernet shield berbasiskan cip ethernet Wiznet W5100. Ethernet library digunakan dalam menulis program agar arduino board dapat terhubung ke jaringan dengan menggunakan arduino ethernet shield. Pada ethernet shield terdapat sebuah slot micro-SD, yang dapat digunakan untuk menyimpan file yang dapat diakses melalui jaringan. Onboard micro-SD card reader diakses dengan menggunakan SD library. Arduino board berkominikasi dengan W5100 dan SD card mengunakan bus SPI (Serial Peripheral Interface). Komunikasi ini diatur oleh library SPI.h dan Ethernet.h. Bus SPI menggunakan pin digital 11, 12 dan 13 pada Arduino Uno. Pin digital 10 digunakan untuk memilih W5100 dan pin digital 4 digunakan untuk memilih SD card.

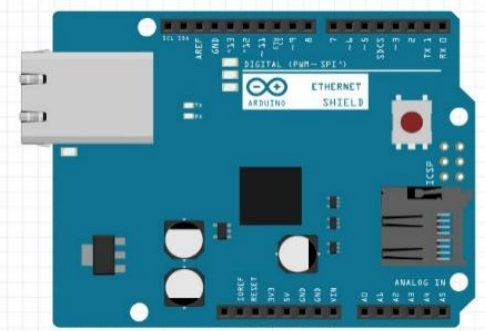

Gambar 3. Arduino Ethernet Shield

\section{Wifi Router}

Wifi Router TP LINK WR741N TP-Link TL-WR741N adalah gabungan kabel / perangkat koneksi jaringan nirkabel yang terintegrasi dengan internet-sharing router dan 4-port switch hub. TL-WR741N Wireless Lite-N Router kompatibel dengan wifi $802.11 \mathrm{~b} / \mathrm{g}$ berdasarkan teknologi $802.11 \mathrm{n}$ dan memberikan kinerja $802.11 \mathrm{n}$ hingga $150 \mathrm{Mbps}$ dengan harga yang lebih terjangkau. Teknologi $11 \mathrm{n}$ dan melebihi kecepatan $11 \mathrm{G}$ memungkinkan aplikasi yang membutuhkan bandwidth yang tinggi seperti video streaming lebih cepat. Untuk lebih jelas perhatikan Gambar 2.9 TP-LINK WR741N kinerja 802.11 hingga $150 \mathrm{Mbps}$ dengan harga yang lebih terjangkau.
Teknologi 11n dan melebihi kecepatan $11 \mathrm{G}$ memungkinkan aplikasi yang membutuhkan bandwidth yang tinggi seperti video streaming lebih cepat. Untuk lebih jelas.

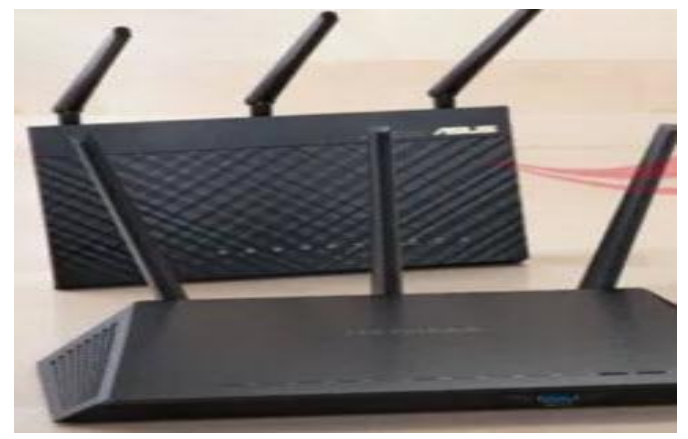

Gambar 2. Wireless Router

D. Web Server

Web server adalah software yang memberikan layanan data yang mempunyai fungsi untuk menerima permintaan HTTP (HyperText Transfer Protocol) atau HTTPS yang dikirim oleh klien melalui web browser dan mengirimkan kembali hasilnya dalam bentuk halaman web yang umumnya berbentuk dokumen HTML (Hyper Text Markup Language). Web server berguna sebagai tempat aplikasi web dan sebagai penerima request dari client.Pada umumnya web server telah dilengkapi pula dengan mesin penerjemah bahasa skrip yang memungkinkan web server menyediakan layanan situs web dinamis dengan memanfaatkan pustaka tambahan seperti PHP (Hypypertext Preprocessor) dan ASP (active Server Pages).

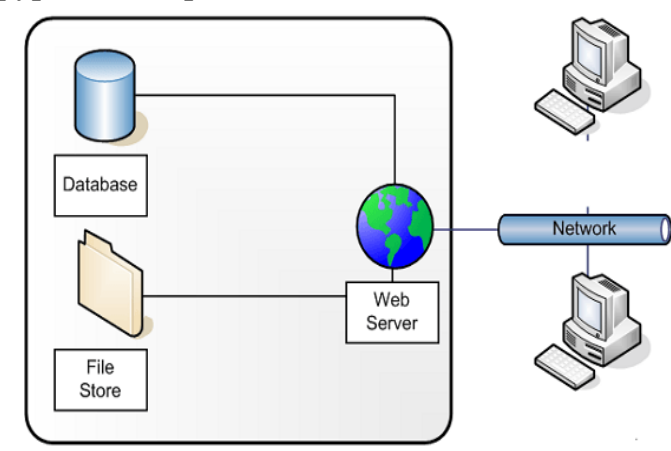

Gambar 4. Arsitektur Web Server

\section{METODE PENELITIAN}

Metode dalam suatu penelitian merupakan cara utama yang digunakan untuk mencapai suatu tujuan penelitian.,agar suatu penelitian berhasil,maka dalam pemilihan metode harus di sesuaikan dengan tujuan dan sifat penelitiannya. Selain itu metode penelitian juga menjelaskan tahapan-tahapan penelitian serta langkah yang dilakukan dalam penelitian. Tahapan-tahapam penelitian sebagai berikut: 


\section{A. Diagram Alur Penyelesaian Masalah}

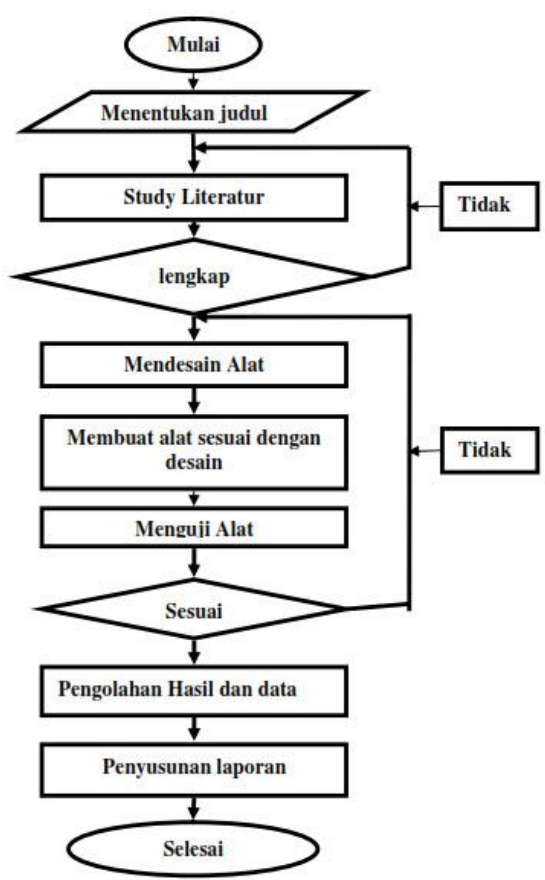

Gambar 5. Diagram Penyelesaian Masalah

1. Melakukan study literatur Mencari literatur antara lain buku-buku tugas akhir,data sheet, buku-buku ilmiah yang sesuai dengan permasalahan yang terdapat pada sistem tempat tidurotomatis.

2. Mulai mencari judul dan pemecahanmasalah

3. Melakukan Pengambilan data-data tentang permasalahan yang ada baik di internet maupun di Intansi RumahSakit.

4. Jika data yang didapat sesuai dengan perancangan alat maka akan dilakukan untuk proses selanjutnya, jika tidak maka akan mengkaji ulang studiliteratur

5. Memulai untuk pendesaianan alat

6. Memulai untuk mengambar sketch alat yang akan digunakan.

7. Melakukan pembuatan alat.

8. Melakukan uji coba terhadap alat yangdigunakan

9. Jika data yang didapat sesuai dengan dilapangan berarti alat berjalan dengan baik

10. Jika data yang diperoleh tidak sesuai maka akan dilakukan perbaikan terhadap hardware dan software

11. Menyimpulkan bahwa alat yang dibuat sesuai

12. Selesai
B. Skema Diagram Sistem Alat

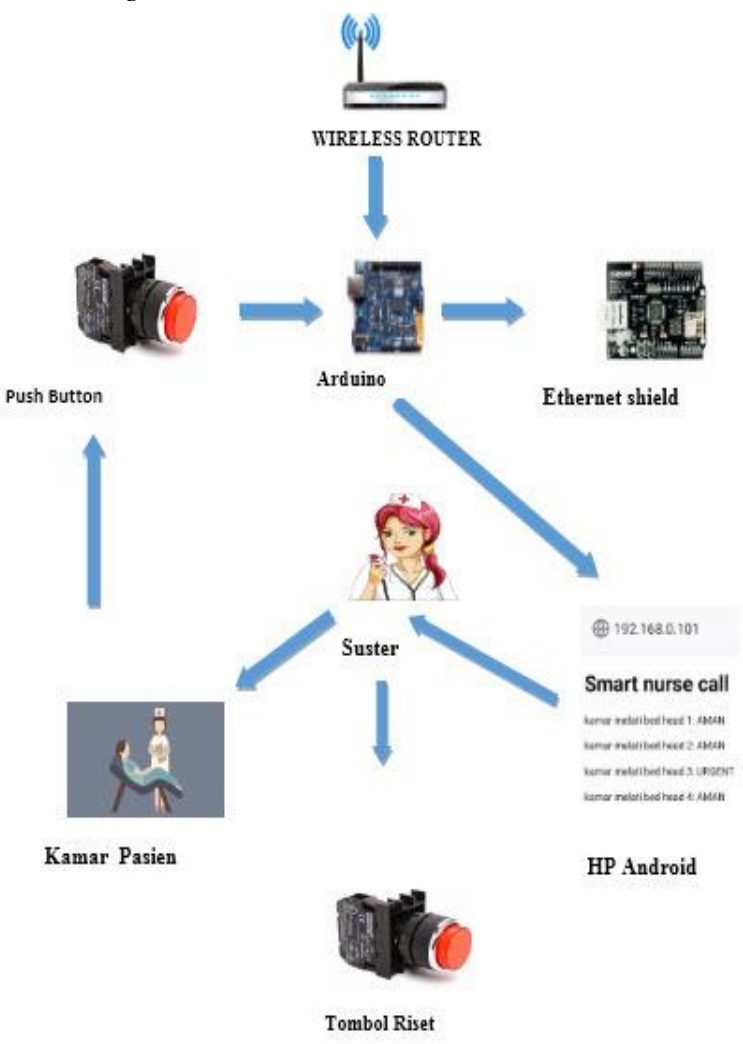

Gambar 6. Blok Diagram System

1. Jika tombol push botton di tekan maka memberi inputan ke arduino

2. Arduino menginialisasi jaringan internet melalui modul ethernet shield.

3. Wifi rooter akan menyambungkan komunikasi antara arduino dan android.

4. Hp android akan memberikan notifikasi berupa tulisan dan suara panggilan pada speaker bahwa pasien di bead head kamar tersebut membutuhkan bantuan.

5. Kemudian perawat akan melihat lampu indikator pada kamar pasien yang menyala pertanda pasien berada di kamar tersebut, setelah pasien tertangani maka perawat akan menekan tombol riset pada kamar pasien sehingga pemberitahuan pada $\mathrm{hp}$ android akan berubah menjadi "AMAN "yang semula keteranganya "URGENT" dan suara panggilan pada speaker juga akan mati. 


\section{Diagram Alir Sistem Alat}

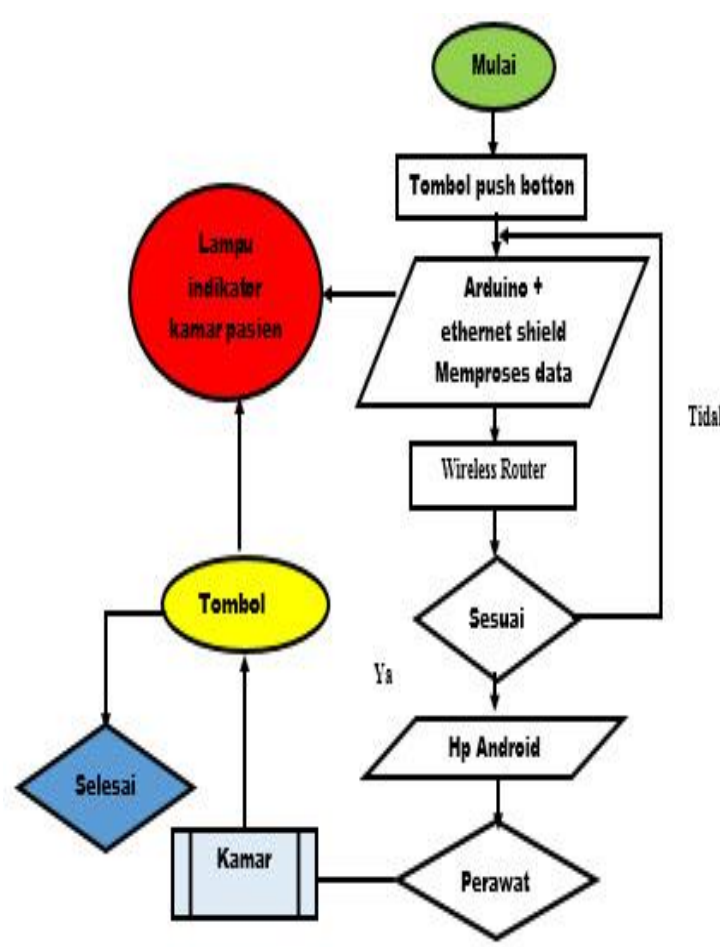

Gambar 7. Diagram Alir Alat

1. Mulai

2. Inisialisasi Alat

3. Arduino akan mendeteksi perintah.

4. Hasil inputan dari tombol push botton akan diolah arduino dan ethernet shiled.

5. Ethernet shield akan menghubungkan wireless router Jika hasil tidak sesuai akan dilakukan pengecekan ulang Arduino,jika berhasil proses akan terhubung Android.

6. Perawat akan datang menuju kamar pasien dan menekan tombol riset maka indikator lampu pada kamar pasien akan mati dan notifikasi tulisan pada hp android akan berubah menjadi "AMAN" yang mulanya "URGENT" dan suara panggilan pada speaker juga akan mati.

7. Selesai.

\section{Perancangan Alat}

Sistem smart nurse call berfungsi untuk memudahkan pasien agar mendapat bantuan atau pertolongan perawat dengan sistem wireless. Mikrokontroler sebagai otak semua dari sistem ini, push button sebagai inputan ke Arduino akan memproses dan Ethernet shield akan menghubungkan perintah Arduino ke web server dan akan memberi informasi berupa pesan bahwa pasien dengan kamar tersebut membutuhkan bantuan dan ada suara panggilan perawat dari speaker serta

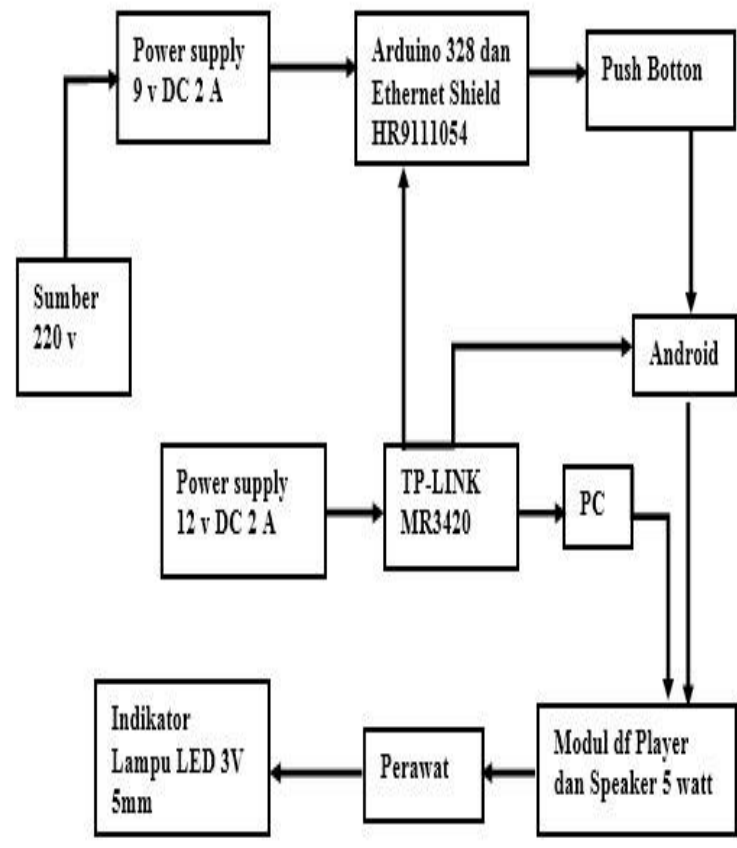

Gambar 8. Diagram Blok System Smart Nurse Call

\section{PENGUJIAN ALAT}

Pengujian alat bertujuan untuk mengetahui apakah alat bekerja sesuai dengan yang diinginkan, untuk mendapatkan hasil yang maksimal.

A. Pengujian Push Button

Bertujuan untuk mengetahui respond alat tersebut terhadap hp android apakah push button dapat memberi inputan kepada hp android.

Tabel 1.

Pengujian Push Botton

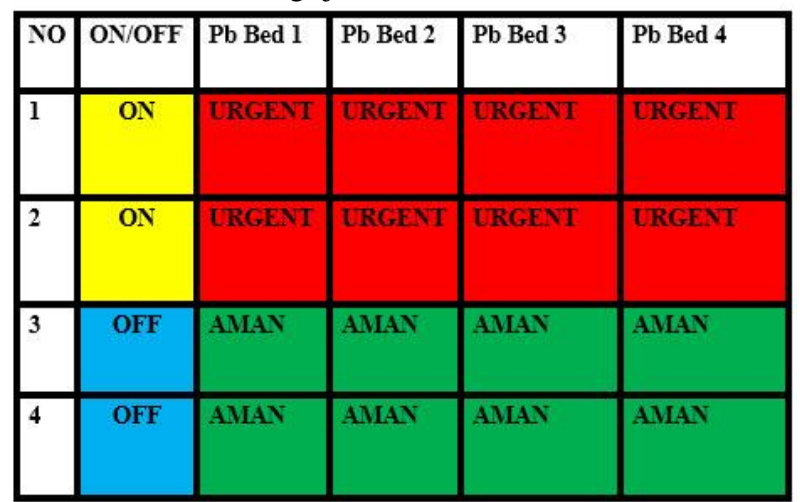

Pada percobaan pertama saat push button bed 1 ditekan maka pada layar $\mathrm{hp}$ android ada keterangan "URGENT" dan pada saat percobaan yang kedua push button bed 2 ditekan maka pada layar hp android ada keterangan "URGENT".

Pada saat percobaan ketiga push button bed 3 tidak ditekan maka pada layar hp android ada keterangan "AMAN" dan pada saat percobaan yang ke empat push 
button bed 4 tidak ditekan maka pada layar hp android ada keterangan "AMAN"

B. Pengujian Push Button Reset

Bertujuan untuk mengetahui respon alat tersebut terhadap Hp android.

Tabel 2.

Pengujian Push Botton Reset

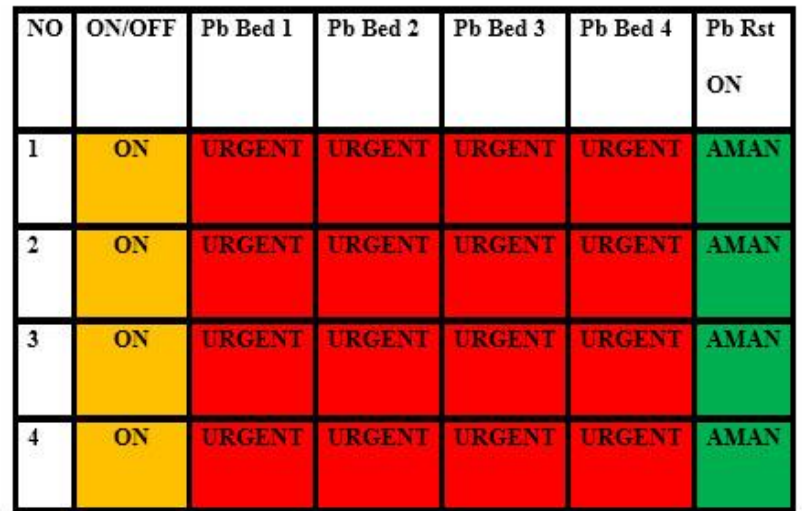

Pada percobaan push button reset ditekan maka indikator keterangan pada layar hp android yang semula "URGENT" maka akan berubah menjadi "AMAN" indikator lampu pada kamar pasien akan mati dan suara panggilan perawat pada speaker juga mati.

C. Pengujian LED pada kamar pasien

Pengujian lampu LED bertujuan untuk mengetahui apakah lampu menyala atau tidak pada saat tombol pasien ditekan.

Pada percobaan pertama pada saat push button 1 ditekan maka LED akan menyala dan akan mati pada saat push button riset ditekan.

Pada percobaan kedua saat push button 2 ditekan maka LED akan menyala dan akan mati pada saat push button riset ditekan.

Pada percobaan ketiga saat push button 3 ditekan maka LED akan menyala dan akan mati pada saat push button riset ditekan.

Pada percobaan keempat push button 4 ditekan maka LED akan menyala dan akan mati pada saat push button riset ditekan.
Tabel 3.

Pengujian LED Pada Kamar Pasien

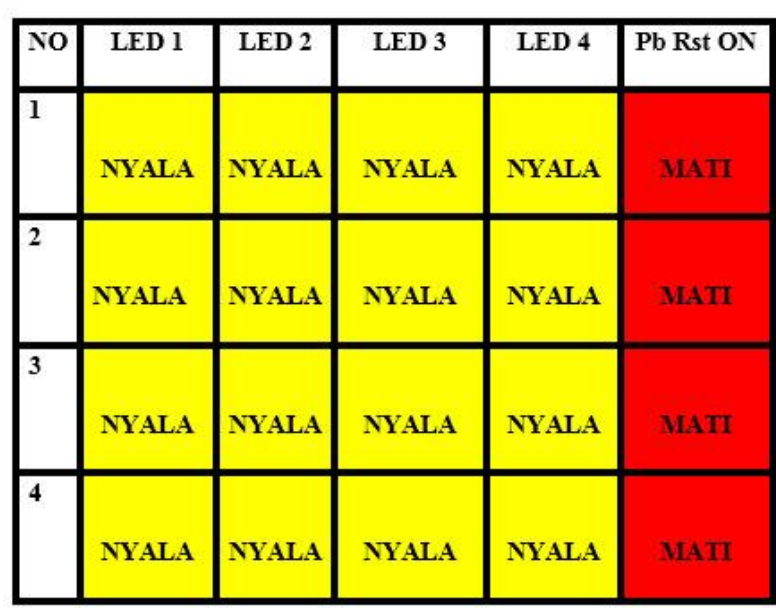

D. Pengujian Jarak Kekuatan Signal wifi Router

Bertujuan untuk mengetahui berapa meter jarak kekuatan signal wifi Router dengan Hp android pada perawat.

Percobaan pertama pada bead head 1 sampai dengan bead head 4 dengan jarak 0-5 Meter signal wifi terhadap hp android responds bagus.

Percobaan kedua pada bead head 1 sampai dengan bead head 4 dengan jarak 5-10 Meter signal wifi terhadap hp android respon bagus.

Percobaan ketiga pada bead head 1 sampai dengan bead head 4 dengan jarak 10-15 Meter signal wifi terhadap hp android respon bagus.

Percobaan keempat pada bead head 1 sampai dengan bead head 4 dengan jarak 15-20 Meter signal wifi terhadap hp android respon bagus.

Percobaan kelima pada bead head 1 sampai dengan bead head 4 dengan jarak 20-25 Meter signal wifi terhadap hp android respon bagus.

Percobaan keenam pada bead head 1 sampai dengan bead head 4 dengan jarak 25-30 Meter signal wifi terhadap hp android respon bagus.

Percobaan ketujuh pada bead head 1 sampai dengan bead head 4 dengan jarak 30-35 Meter signal wifi terhadap hp android

Percobaan kedelapan pada bead head 1 sampai dengan bead head 4 dengan jarak 35-40 Meter signal wifi terhadap hp android lemah. 
Tabel 4.

Pengujian Jarak Kekuatan Wifi Router

\begin{tabular}{|c|c|c|c|c|c|}
\hline NO & Jarak/M & Bed head & $\begin{array}{c}\text { Bed } \\
\text { head 2 }\end{array}$ & $\begin{array}{c}\text { Bed } \\
\text { head 3 }\end{array}$ & $\begin{array}{c}\text { Bed } \\
\text { head 4 }\end{array}$ \\
\hline 1 & $0-5$ METER & & & & $\checkmark$ \\
\hline 2 & 5 -10 METER & & & $\checkmark$ & $\checkmark$ \\
\hline 3 & $10-15$ METER & & & & $\checkmark$ \\
\hline 4 & $15-20$ METER & & & $\checkmark$ & $\checkmark$ \\
\hline 5 & $20-25$ METER & & $\checkmark$ & $\checkmark$ & $\checkmark$ \\
\hline 6 & $25-30$ METER & & & $\checkmark$ & $\checkmark$ \\
\hline 7 & $30-35$ METER & & $\checkmark$ & $\checkmark$ & $\checkmark$ \\
\hline 8 & $35-40$ METER & $\mathrm{X}$ & $\mathrm{X}$ & $\mathrm{X}$ & $\mathrm{X}$ \\
\hline
\end{tabular}

E. Pengujian Hand Phone (HP) Android

Pengujian ini bertujuan untuk mengetahui respon HP Android yang dibawa oleh perawat saat pasien di kamar membutuhkan bantuan.

Gambar berikut menunjukkan tampilan dari HP Android pada perawat ketika pasien sedang membutuhkan bantuan. ( AMAN) berarti kondisi pasien sedang tidak membutuhkan bantuan dan ( URGENT ) berarti kondisi pasien sedang membutuhkan bantuan.

\subsection{8 .0 .101}

\section{Smart nurse call}

\author{
kamar melati bed head 1: AMAN \\ kamar melati bed head 2: AMAN \\ kamar melati bed head 3: URGENT \\ kamar melati bed head 4: AMAN
}

Gambar 9. Tampilan Pada Hp Android

\section{KESIMPULAN}

Dari hasil penelitian ini maka dapat disimpulkan sebagai berikut :

1. Perancangan prototype System smart nurse call menggunakan beberapa komponen utama sebagai input, control dan output. Push botton dirancang untuk memberi input, microcontroler Arduino Uno 328 dan Ethernet shield sebagai pengolah data web atau control dan diteruskan wifi Router MR3420, Modul Df player,Speaker dan Hp Afndroid sebagai output. Dari hasil pengujian tabel 4.1-4.5 didapat 3 parameter pasien dianggap aman jika tampilan pada layar Hp Android (Aman) dan tidak aman Jika (Urgent), Lampu indikator kamar pasien menyala jika pasien membutuhkan bantuan dan mati jika sudah ditangani, bunyi suara panggilan kepada perawat jika pasien sedang membutuhkan bantuan dan suara panggilan mati jika pasien sudah ditangani.

2. Progam web server dibuat menggunakan Bahasa HML yang dimuat dalam progam arduino uno 328 IDE, media ini menggunakan ethernet shield yang terhubung dengan Arduino untuk menginterfacekan perangkat I/O melalui TPC/IP yang saling berkomunikasi satu sama yang lain. Untuk mengaplikasikan monitoring smart nurse call IP sama yang lain. Untuk mengaplikasikan monitoring smart nurse call IP address Tp-Link ( 192.168.0.101 ) diset didalam Hp/ Laptop sebelumnya, kalau sudah terhubung maka secara otomatis monitoring sistem smart nurse call akan muncul pada layar $\mathrm{Hp} /$ Laptop.

\section{VI.SARAN}

Berdasarkan penelitian yang telah dilakukan, maka ada beberapa saran yang dapat dijadikan bahan pertimbangan bagi peneliti selanjutnya diantaranya:

1. Untuk penelitian selanjutnya smart nurse call dapat dikembangkan lebih dari dua Hp.

2. Untuk penelitian selanjutnya agar ditambahkan sistem back up data base pasien supaya ada recordnya pasien berapa aja yang membutuhkan bantuan.

3. Penyediaan sumber daya backup, jika sewaktu - waktu tidak ada sumber listrik utama.

4. Untuk penelitian selanjutnya agar diperbaiki tampilan design web servenya supaya terlihat lebih bagus.

\section{REFERENSI}

[1] Sayekti, "Bel Pemanggil Perawat Berbasis Wireless Menggunakan Xbee," Jurnal Teknik Elektro Terapan, vol. 2, pp. 174-180, 2013.

[2] N. Jamal, "Sistem Pengendali Nurse Station Menggunakan PPI 8255," Jurnal TELEMATIKA 2012.

[3] ASHRAE, Enviromental Guidelines for Datacom Equipment. Diakses 2 Februari 2013.

[4] Purnomo, Hadi.2014.Makalah App Inventor:Ciputat

[5] Roby,"Pemanggil rumah sakit, Android, jelly bean", Internet skripsi teknik elektro tarumanegara 2017.

[6] Ardiyanto,Farit." Alat Pemanggil Perawat dengan Antarmuka RS-485”. Website http://www.atw.ac.id/jurnal/Teknika_Edisi_8_03.pdf, 2008, diakses tanggal 25 Juli 2013 Pukul 18.50.

[7] Santoso Hari,2015 Panduan Praktis Arduino Untuk Pemula. V1

[8] Hannan Arif, "Perancangan Sistem Pemanggil perawat Berbasis Mikrokontroler 16" skripsi 2012.

[9] Kurnia Ihcsan," Analisis Performance Wireless Router Linkys Antara Firmware Original Dan Custom" skripsi 2018. 
[10] Nika Wahyuni," Rancang Bangun Timbangan Digital Dengan Tampilan Harga Dan Output Suara" skripsi 2017.

[11] Ir,Supardi Yuniar dan Maulana Faizal Defri,s.," Buku Mahir Web Progaming" Penerbit PT Elex Media Kompotindo Gramedia,Jakarta 